\title{
Asymptomatic Serosalized Essure Microinsert in the Distal Ileum
}

\author{
Nigel Pereira, MD, Irene Grias, DO, Carl R. Della Badia, DO \\ Department of Obstetrics and Gynecology, Drexel University College of Medicine, Philadelphia, PA, USA (Dr. Pereira). \\ Division of Minimally Invasive Surgery, Department of Obstetrics and Gynecology, Drexel University College of Medicine, \\ Philadelphia, PA, USA (Drs. Grias, Della Badia).
}

\begin{abstract}
Introduction: Perforation of the uterus or fallopian tube during microinsert placement, with subsequent migration of the microinsert into the abdominopelvic cavity, is a known complication.

Case Description: A 38-year-old woman underwent hysteroscopic tubal sterilization with Essure microinserts (Conceptus, Mountain View, California). She returned 4 months later for hysterosalpingography, during which only part of the right microinsert was identified in the right cornu of the uterus. The remaining part of the microinsert was suspected to be in the pelvic cavity. Laparoscopy showed one fragment of the right microinsert projecting from the right cornu; the remaining fragment was incorporated into the serosa of the distal ileum. After an intraoperative consultation with the colorectal surgery team, both fragments of the microinsert were left as is, and tubal fulguration for sterilization was performed.
\end{abstract}

Discussion: Although perforated microinserts can cause small-bowel obstruction or perforation, our case highlights the asymptomatic incorporation of a microinsert into the serosa of the distal ileum.

Key Words: Essure, Hysteroscopy, Complications, Small bowel, Migration.

Citation Pereira N, Grias I, Della Badia CR. Asymptomatic serosalized essure microinsert in the distal ileum. CRSLS e2014.00156. DOI: 10.4293/CRSLS.2014.00156.
Copyright (C) 2014 SLS This is an open-access article distributed under the terms of the Creative Commons Attribution-Noncommercial-ShareAlike 3.0 Unported
license, which permits unrestricted noncommercial use, distribution, and reproduction in any medium, provided the original author and source are credited.
Dr. Della Badia participates on the Speaker's Bureau for Warner Chilcott and is a research investigator for Abbott Laboratories. The other authors have nothing to
disclose.

Address correspondence to: Nigel Pereira, MD, Department of Obstetrics and Gynecology, Drexel University College of Medicine, 245 N 15th St, MS 495, 16th Floor, New College Building, Philadelphia, PA 19102, USA. Telephone: (215) 762-8292, Fax: (215) 762-1470, E-mail: Nigel.Pereira@drexelmed.edu

\section{INTRODUCTION}

Female sterilization is the most common method of contraception worldwide, being used by $19 \%$ of female persons aged 15 to 49 years who are currently married or in a union. ${ }^{1}$ Permanent sterilization methods prevent pregnancy by disrupting fallopian tube patency and include techniques that involve surgical cutting, mechanical blockage, electrical coagulation, or blocking the fallopian tubes with chemicals and microinserts that induce fibrosis. ${ }^{2}$ The Essure system (Conceptus, Mountain View, California) uses microinserts that are placed by hysteroscopy into the proximal portions of each fallopian tube, where they induce fibrotic tubal occlusion. ${ }^{3,4}$ Despite its safety and technical feasibility, complications are known to occur in up to $3 \%$ of women undergoing this method of permanent sterilization. ${ }^{4}$ Perforation of the uterus or fal- lopian tube during microinsert placement, with subsequent migration of the microinsert, is a well-documented complication that may or may not cause symptoms. ${ }^{4-6}$

We searched PubMed, Ovid, Embase, and Google Scholar for all English-language articles published between 2000 and 2013 using the following search terms: Essure, small bowel, complications, and migration. Our search found 2 cases of small-bowel obstruction or perforation related to Essure microinserts. 5,6 On the basis of our search, this report represents the first case of asymptomatic incorporation of an Essure microinsert in the serosa of the distal small bowel.

\section{CASE}

A 38-year-old multiparous woman, aborta 1, with an unremarkable gynecologic, medical, and surgical history, presented to our office for hysteroscopic sterilization. By 


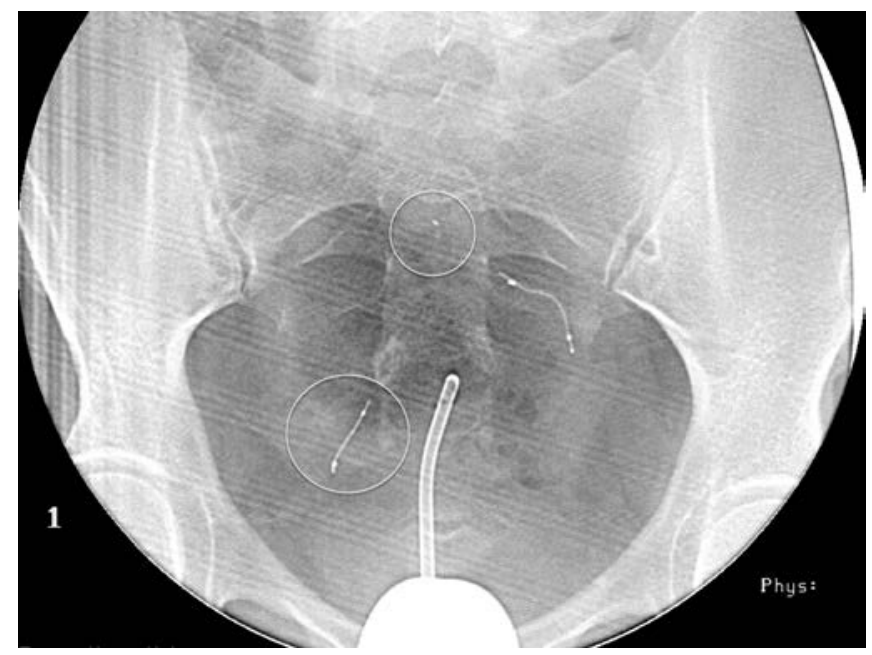

Figure 1. HSG shows two parts of the right microinsert (circles).

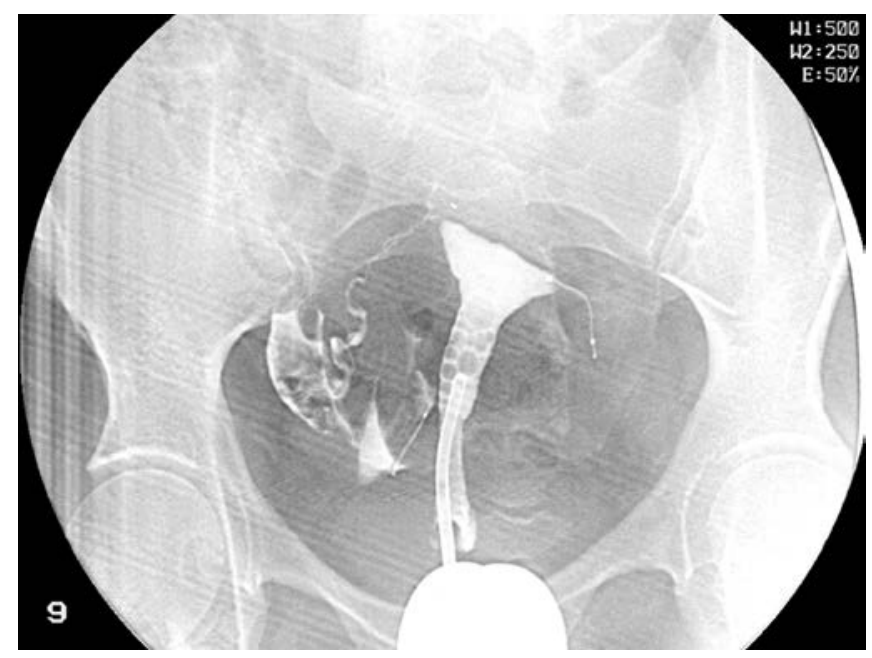

Figure 2. HSG shows free spillage of radiographic dye through the right fallopian tube.

use of a 5.5-mm $30^{\circ}$ hysteroscope, a grossly normal intrauterine cavity and bilateral ostia were visualized. The Essure microinserts were placed in the proximal portion of both fallopian tubes without difficulty. At the end of the procedure, 3 coils were noted at the right ostium and 7 coils at the left ostium.

The patient returned 4 months later for hysterosalpingography (HSG) to confirm tubal occlusion. At this visit, she denied abdominal or pelvic pain. After intrauterine injection of radiographic dye, the left microinsert was found to be in an anatomically correct position, with blockage of dye through the fallopian tube. The right microinsert, however, appeared to be in two places. One part of the microinsert was identified in the right cornu of the uterus,

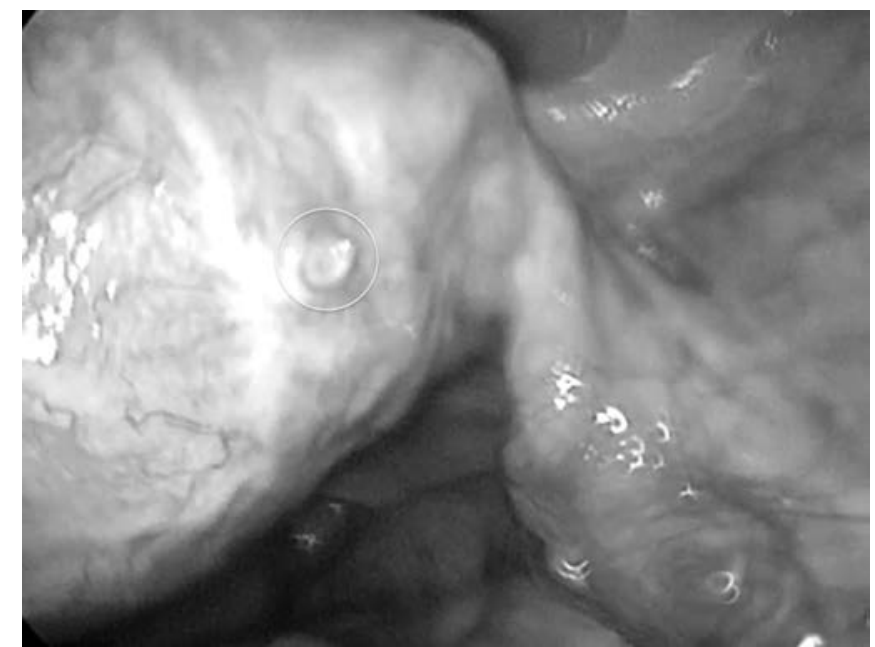

Figure 3. Laparoscopic findings of smaller microinsert fragment projecting from right cornu of uterus (circle).

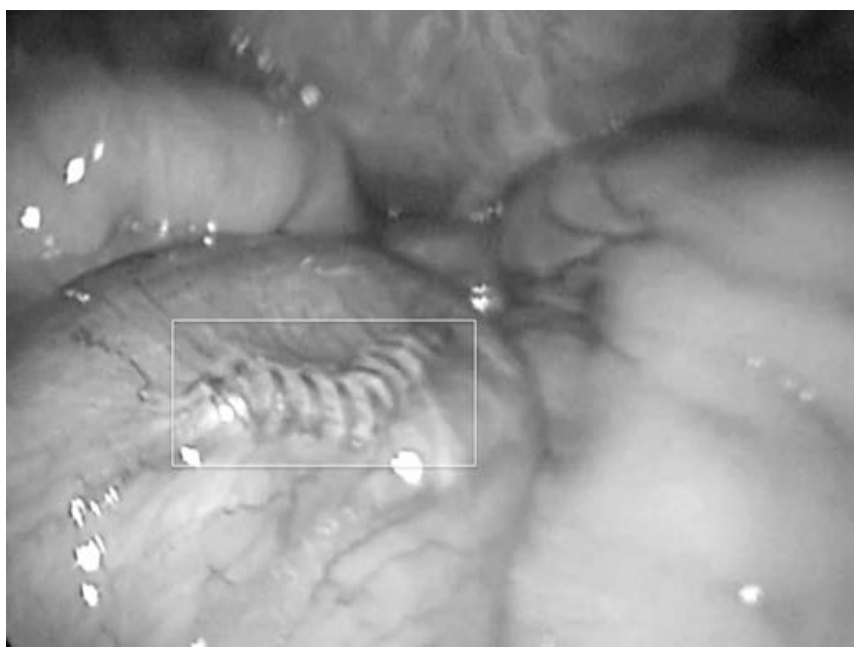

Figure 4. Laparoscopic findings of larger microinsert incorporated into serosa of distal ileum (rectangle).

whereas the other part was in an unspecified area in the pelvic cavity (Figure 1). Free spillage of radiographic dye was noted through the right fallopian tube (Figure 2). The findings were reviewed in detail with the patient.

The patient returned to the office to discuss other methods of sterilization. On the basis of this discussion, she elected to undergo tubal fulguration through the laparoscopic approach. A 5-mm umbilical port was placed, and a $30^{\circ}$ laparoscope was used to perform a primary survey of the pelvic anatomy; no gross abnormalities were noted. On closer inspection of the right cornu of the uterus, a projecting serosalized fragment of the microinsert was noted (Figure 3). The second fragment of the microinsert was found incorpo- 
rated in the serosa of the distal ileum (Figure 4). The microinsert did not move with peristalsis, and there was no evidence of bowel perforation, strangulation, inflammation, or dilatation. Furthermore, no blood or pus was noted in the abdominopelvic cavity, with the remainder of the bowel appearing grossly normal. An intraoperative consultation with the colorectal surgery team was requested, and a detailed discussion about removal of the microinsert and a possible bowel resection ensued. On the basis of the recommendations made by the colorectal surgeons, as well as the low likelihood of further migration of the microinsert fragment, we decided to leave both fragments of the microinsert as is. We subsequently performed tubal fulguration with bipolar cautery for sterilization. The patient tolerated the procedure well and was informed of all intraoperative findings. She made an uneventful recovery and had no complaints during her subsequent postoperative visits 2 weeks later. During her annual gynecologic visit 1 year later, the patient denied new clinical symptoms.

\section{DISCUSSION}

After its approval by the Food and Drug Administration in 2002, the Essure system has become an increasingly popular method of female sterilization worldwide.6,7 The Essure system comprises expanding microinserts that are placed within the proximal portions of the fallopian tubes under hysteroscopic visualization. ${ }^{3}$ The microinserts consist of a nickel-titanium alloy outer coil, as well as a flexible stainless steel inner coil that is surrounded by white polyethylene terephthalate fibers, that incites benign tissue ingrowth by a fibrotic reaction when in contact with tissue. ${ }^{8}$ Over a 3 -month period, the fibrotic reaction leads to tubal occlusion. In addition to the reported efficacy of $99.87 \%$, this mode of sterilization can be performed in the office in a safe and technically feasible manner, with a successful placement rate of $94 \%$ during the first attempt.9,10

Despite these advantages, complications associated with microinsert placement do occur, the most serious of which include perforation and microinsert migration. Perforation of the uterus or fallopian tube at the time of microinsert placement occurs in up to $\sim 2 \%$ of cases. ${ }^{11}$ Possible causes of perforation include poor visualization during device placement, tubal spasm, or uterine and tubal abnormalities. ${ }^{5,11}$ In these settings the microinsert is less likely to track along the fallopian tube, thereby increasing the likelihood for perforation. ${ }^{6,11}$ Migration of microinserts after placement is extremely rare, with an estimated incidence of $0.1 \%{ }^{11}$
Although current data indicate that long-term adverse events are not associated with microinsert perforation and migration, microinsert-induced bowel perforation and bowel obstruction have been described in the medical literature. ${ }^{4-6}$ Mantel et $\mathrm{al}^{5}$ recently published a case of small-bowel obstruction and perforation occurring 1 month after Essure microinsert placement. At laparotomy, the microinsert that had migrated was found ensnaring the terminal ileum, where it had caused strangulation and local perforation of the bowel wall. After removal of the device, an ileocecal resection with side-to-side ileocolostomy was performed. Similarly, Belotte et $\mathrm{al}^{6}$ presented a case of small-bowel obstruction related to an Essure microinsert that had migrated 1 month after placement. In this case laparoscopy showed that the microinsert was adherent to the lateral aspect of the mid ileum, which was the focal point of obstruction because of adhesions. The patient underwent adhesiolysis, left salpingectomy, appendectomy, and removal of the microinsert that had migrated. In both cases perforation at the time of microinsert placement was hypothesized to be the reason for abdominal migration of the device.

Consistent with the aforementioned cases, our patient underwent seemingly uncomplicated placement of Essure microinserts. As in the other cases, we postulate that perforation of the uterus or fallopian tube occurred at the time of microinsert placement. In contrast to the other cases, however, our patient remained asymptomatic despite incorporation of the microinsert into the serosa of the distal ileum. We suspect that after perforation of the uterus or fallopian tube, breakage and subsequent abdominal migration of the microinsert occurred. It is also possible that the fragmented microinsert may represent a device failure. Although the reasons for breakage of the microinsert remain uncertain, we postulate that the fragment of the microinsert that had migrated may have settled on the distal ileum, where it induced a fibrotic reaction to become incorporated within the serosa. Because the microinsert did not strangle or directly damage the small bowel, the patient remained asymptomatic. Belotte et $\mathrm{al}^{6}$ suggest removal of the microinsert from the peritoneal cavity as soon as misplacement is diagnosed, in light of peritoneal adhesions and the possibility of small-bowel obstruction. Although we strongly considered this management option in our patient, we were dissuaded by our colorectal surgery colleagues because of the patient's lack of symptoms and the lack of detailed informed consent about bowel resection that may have been necessary to remove the microinsert. 
Our case remains consistent with the lack of long-term adverse events associated with perforation or migration of the Essure microinsert. ${ }^{4}$ Furthermore, our case highlights the importance of follow-up HSG. Given the fact that uterine or fallopian tube perforation may not be detected at the time of hysteroscopic placement of the Essure microinsert, follow-up HSG serves as an important imaging tool to confirm proper microinsert placement and tubal occlusion. As highlighted by our case, HSG findings of improperly placed microinserts or microinserts that have migrated warrant further laparoscopic investigation and an alternate form of sterilization. ${ }^{11}$

\section{References:}

1. United Nations, Department of Economic and Social Affairs, Population Division http://www.un.org/esa/population/publications/ contraceptive2011/contraceptive2011.htm. Accessed April 7, 2013.

2. Lawrie TA, Nardin JM, Kulier R, Boulvain M. Techniques for the interruption of tubal patency for female sterilisation. Cochrane Database Syst Rev. 2011;(2):CD003034.

3. Franchini M, Boeri C, Calzolari S, et al. Essure transcervical tubal sterilization: a 5-year x-ray follow up. Fertil Steril. 2011; 95(6):2114-2115.

4. Cooper JM, Carignan CS, Cher D, Kerin JF; Selective Tubal Occlusion Procedure 2000 Investigators Group. Microinsert non- incisional hysteroscopic sterilization. Obstet Gynecol. 2003; 102(1):59-67.

5. Mantel HT, Wijma J, Stael AP. Small bowel obstruction and perforation after Essure sterilization: a case report. Contraception. 2013;87(1):121-123.

6. Belotte J, Shavell VI, Awonuga AO, Diamond MP, Berman JM, Yancy AF. Small bowel obstruction subsequent to Essure microinsert sterilization: a case report. Fertil Steril. 2011;96(1): e4-e6.

7. U.S. Food and Drug Administration. http://www.fda.gov/ medicaldevices/productsandmedicalprocedures/deviceapprovals andclearances/recently-approveddevices/ucm083087.htm. Accessed April 7, 2013.

8. Gerritse MB, Veersema S, Timmermans A, Brölmann HA. Incorrect position of Essure microinserts 3 months after successful bilateral placement. Fertil Steril. 2009;91(3):930.e1-930.e5.

9. Levy B, Levie MD, Childers ME. A summary of reported pregnancies after hysteroscopic sterilization. J Minim Invasive Gynecol. 2007;14(3):271-274.

10. Panel P, Grosdemouge I. Predictive factors of Essure implant placement failure: prospective, multicenter study of 495 patients. Fertil Steril. 2010;93(1):29-34.

11. Guelfguat M, Gruenberg TR, Dipoce J, Hochsztein JG. Imaging of mechanical tubal occlusion devices and potential complications. Radiographics. 2012;32(6):1659-1673. 